\title{
Recherche d'une méthode fiable de culture de protoplastes, d'hybridation somatique et de régé- nération chez Medicago
}

\author{
Evelyne TÉOULÉ, Yvette DATTÉE \\ Laboratoire d'Amélioration des Plantes, Université Paris XI, 91405 Orsay Cedex
}

RÉSUMÉ

\begin{abstract}
La maîtrise des techniques de culture de protoplastes et d'hybridation somatique dans le genre Medicago présente un grand intérêt tant au plan agronomique, pour être intégrée dans les schémas d'amélioration, qu'au plan fondamental pour une meilleure connaissance du genre.

Cet article présente les recherches effectuées pour la mise au point d'une méthode de culture des protoplastes et d'une technique d'hybridation somatique, compatibles avec la régénération de plantes et non spécifiques d'un génotype particulier. Les espèces étudiées sont Medicago sativa et Medicago falcata. Les facteurs conditionnant la régénération sont décrits : culture des plantes, techniques d'isolement, conditions de culture des protoplastes puis des cals et des embryons. La technique de fusion est détaillée : nature de l'agent de fusion, modalités de la fusion.
\end{abstract}

Mots clés additionnels : Fusion somatique, Medicago sativa, Medicago falcata. regeneration in the genus Medicago.

\begin{abstract}
The mastery of protoplast culture and somatic hybridization techniques in the genus Medicago would be of great interest for agronomic purposes (integration into breeding strategies) and also for fundamental knowledge of the genus. This paper presents research on protoplast culture and somatic hybridization aimed at developing methods compatible with regeneration but independent of genotype. The studied species were Medicago sativa and Medicago falcata. Protoplast source plants had to be pretreated with a short photoperiod for at least 15 days before protoplast isolation. Protoplasts were isolated from young leaves, by slow incubation in a modification of the enzyme solution of KAO \& MichayLUK (1980). The best culture medium was derived from that of KaO \& MichaYluK (1980), modified for glucose concentration. Culture density was around 50.000 protoplasts $/ \mathrm{ml}$. The best temperature was $28{ }^{\circ} \mathrm{C}$. The method used to sustain division is described in detail because this seems to be a very important factor. By this technique we obtained calli and embryos and were able to regenerate plants. Concerning somatic hybridization, two fusing agents were tested : polyethylene glycol (PEG) and calcium chloride. The fusion rate was about $20 \%$ with PEG but almost all the protoplasts died after this treatment. With calcium chloride, the fusion rate was lower $(10 \%)$, but the viability of the treated protoplasts was good. In addition, this process allowed us to regenerate plants, and even somatic hybrid plants. This is the reason why somatic hybridization is now considered to be usable in Medicago breeding.
\end{abstract}

Additional key words : Somatic fusion, Medicago sativa, Medicago falcata.

\section{INTRODUCTION}

La famille des Légumineuses est réputée poser beaucoup de problèmes en culture in vitro. La régénération de plantes entières à partir de cals issus d'explants somatiques n'a été réussie que chez quelques espèces : Medicago sativa L. (SAUNDERS \& BinGHAM, 1972, 1975 ; MAC COY \& BINGHAM, 1977 ; KAO \& MICHAYLUK, 1981), Trifolium repens L. (PELLETIER G. \& PELLETIER A., 1971 ; OSWALD et al., 1977), Trifolium pra- tense L. (PHILliPS \& COLLINS, 1978 ; BEACH \& SMITH, 1979), Trifolium alexandrinum L. (MOKHTARZADEH \& CONSTANTIN, 1978), Pisum sativum L. (MAlmBerg, 1979 ; JACOBSEN \& KYSELY, 1984), Glycine canescens F. J. HERM (KAMEYA \& WILDHOLM, 1981), Vicia faba L. (GALZY \& HAMOUI, 1981), Stylosanthes humilis H. B. K. (MEIJER, 1982), Onobrychis vicifolia Scop. L. (ARCIONI \& MARIOTTI, 1983), Lotus corniculatus L. (MARIOTTI et al., 1984).

Medicago sativa, l'un des matériels les mieux con- 
nus, a fait l'objet de nombreux travaux sur la régénération (BINGHAM et al., 1975 ; REISCH \& BINGHAM, 1980 ; WALKER \& SATO, 1978, 1979, 1981 ; LUPOTTO, 1983 ; HARTMAN et al., 1984 ; STUART et al., 1984 ; MitTEN et al., 1984 ; BROWN \& ATANASSOV, 1985).

En ce qui concerne la culture de protoplastes, des régénérations de plantes ont été obtenues sur Medicago sativa (KAO \& MiCHAYLUK, 1980 ; DOS SANTOS et al., 1980 ; JOHNSON et al., LU et al., 1982 ; XU et al., 1981 ; PEZzOTTI et al., 1984), Medicago coerulea GRASSH et $M$. glutinosa MARSCHALL VON BIEBERSTEIN (ARCIONI et al., 1982), Medicago arborea L. (MARIOTTI et al., 1984), Trifolium repens (GRESSHOFF, 1980), Trigonella corniculata L. (LU et al., 1982), Lotus corniculatus (AHUYA et al., 1983; MARIOTTI et al., 1984), Trifolium rubens L. (GROSSER \& Collins, 1984).

Le plus souvent les techniques mises au point sont spécifiques de certains génotypes ce qui limite leur utilisation dans les programmes d'amélioration génétique. De plus, les résultats relatifs à la régénération de plantes après une opération de fusion sont encore très rares chez les Légumineuses puisque ce n'est que récemment qu'il a été fait état d'un hybride somatique entre 2 espèces du genre Medicago (TÉoulé, 1983a-b).

L'objectif est ici de présenter les premières étapes d'une recherche visant à intégrer l'hybridation somatique interspécifique dans le schéma d'amélioration de la luzerne cultivée : l'adaptation de la technique de régénération après culture de protoplastes à une gamme diversifiée de génotypes de $M$. sativa et de $M$. falcata, et la mise au point d'une méthode d'hybridation somatique compatible avec la régénération.

\section{PRINCIPAUX FACTEURS CONDITIONNANT LA RÉGÉNÉRATION}

\section{A. Conditionnement des plantes}

Chez $M$. sativa, tétraploïde, ont été utilisés 2 cultivars : Europe et Verneuil, 3 populations : la popula- tion flamande, la population provence et une population chinoise, et 9 clônes mâles stériles cytoplasmiques d'origines diverses. Chez $M$. falcata tétraploïde, 2 populations ont été étudiées.

Les boutures sont cultivées en vermiculite et arrosées à l'eau désionisée. Une solution nutritive est apportée 2 fois par semaine. Plusieurs conditions de température et de photopériode ont été expérimentées (tabl. 1). Mis à part les génotypes issus de la population chinoise qui produisent toujours de très bons rendements et une bonne efficacité d'étalement, le comportement de l'ensemble des autres génotypes dépend beaucoup des conditions photopériodiques. Les meilleurs résultats sont obtenus avec une photopériode alternative $16 \mathrm{~h} / 9 \mathrm{~h}$ : les plantes croissent initialement en $16 \mathrm{~h}$ de jour puis sont transférées en $9 \mathrm{~h}, 15$ jours au minimum avant le prélèvement des feuilles.

\section{B. Isolement des protoplastes}

Les feuilles sont prélevées à un stade jeune mais lorsqu'elles sont déjà bien dépliées. Elles sont rincées au teepol et stérilisées à l'hypochlorite de calcium à $7 \%$ pendant $20 \mathrm{mn}$ puis rincées 3 fois à l'eau distillée stérile.

L'épiderme inférieur est ôté et la face pelée est déposée à la surface d'une solution enzymatique. L'incubation a toujours lieu à l'obscurité et à $26^{\circ} \mathrm{C}$ environ. Deux durées d'incubation, chacune associée à une solution particulière ont été testées (tabl. 2).

Pour l'ensemble des génotypes, l'incubation lente dans la solution $\mathrm{E}_{1}$ est apparue préférable. Elle conduit à un meilleur rendement : $15.10^{6}$ protoplastes par gramme de poids frais contre $6.10^{6}$ après l'incubation rapide. De plus, les protoplastes sont moins fragiles et ont une efficacité d'étalement 2 fois plus élevée qu'après l'incubation rapide.

TABLEAU 1

Influence des conditions de culture des plantes mères (température et photopériode), sur le rendement (R) et la division des protoplastes. Résultats qualitatifs relatifs à l'ensemble des génotypes de $\mathrm{M}$. sativa et de $\mathrm{M}$. falcata.

Influence of culture conditions of the protoplast source plants (temperature and photoperiod) on the yield (R) and the plating efficiency of protoplasts. Qualitative results relating to all the genotypes of $\mathrm{M}$. sativa and $\mathrm{M}$. falcata.

\begin{tabular}{|c|c|c|c|c|}
\hline$N^{\mathrm{Te}}$ & $18^{\circ} \mathrm{C}$ & $22{ }^{\circ} \mathrm{C}$ & $24{ }^{\circ} \mathrm{C}$ jour $/ 17^{\circ} \mathrm{C}$ nuit & $<25^{\circ} \mathrm{C}$ Serre non régulée \\
\hline $16 \mathrm{~h}$ & $\begin{array}{c}\mathrm{R}<0,5 \cdot 10^{6} / \mathrm{g} \\
\text { débris : nombreux } \\
\text { pas de divisions }\end{array}$ & $\begin{array}{c}5.10^{6} / \mathrm{g}<\mathrm{R}<10^{7} / \mathrm{g} \\
\text { débris : peu } \\
\text { E.E. }<10 \%\end{array}$ & $\begin{array}{c}5.10^{6} / \mathrm{g}<\mathrm{R}<10^{7} / \mathrm{g} \\
\text { débris : peu } \\
\text { E.E. }<10 \%\end{array}$ & $\begin{array}{c}10^{6} / \mathrm{g}<\mathrm{R}<2.10^{6} / \mathrm{g} \\
\text { débris : peu } \\
\text { pas de divisions }\end{array}$ \\
\hline $9 \mathrm{~h}$ & $\begin{array}{c}\mathrm{R}<0,5 \cdot 10^{6} / \mathrm{g} \\
\text { débris : nombreux } \\
\text { pas de divisions }\end{array}$ & $\begin{array}{c}\mathrm{R}>10^{7} / \mathrm{g} \\
\text { débris : peu } \\
10 \%<\text { E.E. }<20 \%\end{array}$ & & $\begin{array}{l}5.10^{6} / \mathrm{g}<\mathrm{R}<10^{7} / \mathrm{g} \\
10 \%<\text { E.E. }<20 \%\end{array}$ \\
\hline $\begin{array}{c}\text { *alternatif } \\
16 \mathrm{~h} / 9 \mathrm{~h}\end{array}$ & & $\begin{array}{l}\mathrm{R}>10^{7} / \mathrm{g} \\
\text { débris : peu }\end{array}$ & E.E. $>25 \%$ & \\
\hline
\end{tabular}

E.E. = efficacité d'étalement.

* Les températures $22^{\circ} \mathrm{C}$ et $\left(24^{\circ} \mathrm{C} / 17^{\circ} \mathrm{C}\right)$ correspondent respectivement aux superserres du phytotron en $9 \mathrm{~h}$ et $16 \mathrm{~h}$ d'éclairement. Le traitement alternatif $16 \mathrm{~h} / 9 \mathrm{~h}$ concerne uniquement ces conditions de température. 


\section{TABLEAU 2}

Mode d'incubation et composition des solutions enzymatiques testées pour l'obtention des protoplastes de feuilles de luzerne.

Incubation method and composition of enzyme solutions tested to obtain mesophyll protoplasts of alfalfa.

\begin{tabular}{|c|c|c|}
\hline $\begin{array}{l}\text { Mode d'incu- } \\
\text { Compo- } \\
\text { sants }\end{array}$ & $\begin{array}{c}\text { Incubation lente } \\
(16 \mathrm{~h}) \\
\text { Solution E1 } \\
\%\end{array}$ & $\begin{array}{c}\text { Incubation rapide } \\
(6 \mathrm{~h}) \\
\text { Solution E2 } \\
\%\end{array}$ \\
\hline Cellulase R-10 & 1 & 5 \\
\hline Macerozyme & 0,5 & 1,25 \\
\hline Rhozyme & 1 & - \\
\hline Mannitol & 5,5 & 11 \\
\hline Sorbitol & 5,5 & - \\
\hline Tampon M.E.S. & 0,058 & - \\
\hline Sels minéraux & - & $\begin{array}{l}\text { Sels de Frearson } \\
\text { (FrEARSON et al. } \\
\text { 1973) }\end{array}$ \\
\hline $\begin{array}{l}\mathrm{pH} \text { et mode d'ajuste- } \\
\text { ment }\end{array}$ & $5,6 / \mathrm{NaOH}$ & $5,6 / \mathrm{NaOH}$ \\
\hline pt de stérilisation & $\begin{array}{l}\text { Solution stérilisée } \\
\text { par filtration }\end{array}$ & $\begin{array}{l}\text { Solution stérilisée } \\
\text { par filtration }\end{array}$ \\
\hline $\begin{array}{l}\text { Dilution avec milieu de } \\
\text { culture }\end{array}$ & Proportions 1: 1 & Aucune \\
\hline
\end{tabular}

Les pourcentages sont exprimés en poids/volume.

La composition des solutions enzymatiques est inspirée de celle de Kao \& Michayluk (1980) et de celle de Dos Santos et al. (1980).

Percentages expressed in weight/volume.

Composition of enzyme solutions derived from those of $K A O \&$ MICHAYLUK (1980) and DOS SANTOS et al., (1980).

\section{Composition du milieu}

Trois milieux ont été testés (tabl. 3a, 3b). Excepté des différences sur le taux de bourgeonnement (souvent associé à un faible taux de division), les protoplastes des différents génotypes se comportent sensiblement de la même façon sur un même milieu. Toutefois, ce n'est que sur le milieu $\mathrm{K}_{77}$ que des divisions suivies de formation de cals ou d'embryons ont été obtenues.

\section{Nature et concentration des sucres}

Les protoplastes de mésophylle de feuilles de luzerne sont assez tolérants et survivent au moins $48 \mathrm{~h}$ lorsque la pression osmotique est comprise entre $550 \mathrm{~m}$ Os et $800 \mathrm{~m}$ Os.

Les effets de la nature du sucre ont été recherchés avec, comme milieu de base, le milieu $K_{77}$. Le saccharose employé seul ou avec du mannitol induit rapidement la mort des protoplastes. Par contre, associé ou non au mannitol, le glucose est bien toléré. Les divisions se poursuivent toutefois plus régulièrement lorsque le glucose est employé seul.

Le milieu retenu pour convenir à l'ensemble des génotypes est à $795 \mathrm{~m}$ Os, il comprend du glucose $(110,4 \mathrm{~g} / 1$ soit $0,61 \mathrm{M})$ et les 9 sucres, employés en faible quantité par KAO (1977). L'adjonction de ces 9 sucres améliore l'efficacité d'étalement et la rapidité d'apparition de la première division.

\section{Nature et concentration des régulateurs de crois- sance}

La composition hormonale du milieu de KAO (KAO, 1977) a été retenue. L'importance de la zéatine pour tous les génotypes de $M$. sativa et de $M$. falcata utilisés est à signaler : si on supprime cette cytokinine, l'efficacité d'étalement est voisine de 0 .

\section{Substances organiques}

L'hydrolysat de caséine et les acides organiques (KAO, 1977), ont un effet bénéfique sur le taux de division. Par contre, et contrairement à KAO (1977), aucune amélioration n'est observée après apport de lait de coco.

\section{4. $p H$ et stérilisation du milieu}

Un $\mathrm{pH}$ de 5,7 donne les meilleurs résultats, il est ajusté par $\mathrm{NaOH}$. Le milieu est stérilisé par filtration sur membrane millipore $0,45 \mu$.

TABLEAU 3a

Premiers stades de l'évolution de la culture de protoplastes de feuilles de luzerne : résultats obtenus sur les milieux $B_{5}(a), K M_{8} P(b)$ et $K_{77}(c)$ First stages of evolution of alfalfa mesophyll protoplast culture : results on medium $B_{5}(a), K M_{8} P(b)$ and $K_{77}(c)$.

\begin{tabular}{|c|c|c|c|}
\hline Génotypes Milieux & $\mathrm{B}_{5}$ & $\mathrm{KM}_{8} \mathrm{P}$ & $\mathrm{K}_{77}$ \\
\hline $\begin{array}{l}\text { Medicago sativa } \\
\text { à l'exception de la } \\
\text { population chinoise. }\end{array}$ & $\begin{array}{l}\text { Reconstitution des parois. } \\
\text { Pas de divisions. }\end{array}$ & $\begin{array}{l}\text { Reconstitution des parois. } \\
\text { Nombreux bourgeonnements. } \\
\text { Quelques divisions. }\end{array}$ & $\begin{array}{l}\text { Reconstitution des parois. } \\
\text { Divisions continues. } \\
\text { Formation de cals ou d'embryons. }\end{array}$ \\
\hline $\begin{array}{l}\text { Medicago sativa. } \\
\text { Population chinoise. }\end{array}$ & $\begin{array}{l}\text { Reconstitution des parois. } \\
\text { Quelques divisions. }\end{array}$ & $\begin{array}{l}\text { Reconstitution des parois. } \\
\text { Nombreux bourgeonnements. } \\
\text { Quelques divisions. }\end{array}$ & $\begin{array}{l}\text { Reconstitution des parois. } \\
\text { Nombreux bourgeonnements. } \\
\text { Divisions continues et formation } \\
\text { d'embryons. }\end{array}$ \\
\hline Medicago falcata. & Non testé. & $\begin{array}{l}\text { Reconstitution de quelques parois. } \\
\text { Quelques divisions «étirées " } \\
\text { s'arrêtant rapidement. }\end{array}$ & $\begin{array}{l}\text { Reconstitution des parois. } \\
\text { Pas de bourgeonnement. } \\
\text { Divisions continues et formation } \\
\text { d'embryons. }\end{array}$ \\
\hline
\end{tabular}

a) GAMBORG et al., 1968.

b) KaO \& Michayluk, 1975.

c) $\mathrm{KAO}, 1977$ 
TABLEAU $3 \mathrm{~b}$

Composition des milieux de culture.

Composition of culture media.

\begin{tabular}{|c|c|c|c|c|c|c|}
\hline $\mathrm{mg} / \mathrm{l}$ & $\mathrm{K}_{77}$ & $\mathrm{~K}_{4}$ & $\mathrm{KM}_{8} \mathrm{P}$ & $\mathrm{K}_{795}$ & $\mathrm{~B}_{5}$ & A \\
\hline \multicolumn{7}{|l|}{ Macro-éléments } \\
\hline $\begin{array}{l}\mathrm{NaH}_{2} \mathrm{PO}_{4}, \mathrm{H}_{2} \mathrm{O} \\
\mathrm{KH}_{2} \mathrm{PO}_{4}, \mathrm{H}_{2} \mathrm{O} \\
\mathrm{CaCl}_{2}, 2 \mathrm{H}_{2} \mathrm{O} \\
\mathrm{KNO}_{3} \\
\mathrm{NH}_{4} \mathrm{NO}_{3} \\
\left(\mathrm{NH}_{4}\right)_{2} \mathrm{SO}_{4} \\
\mathrm{MgSO}_{4} \\
\mathrm{KH}_{2} \mathrm{PO}_{4} \\
\mathrm{KCl}\end{array}$ & $\begin{array}{c}- \\
- \\
600,00 \\
900,00 \\
600,00 \\
- \\
300,00 \\
170,00 \\
300,00\end{array}$ & $\begin{array}{c}- \\
- \\
600,00 \\
1900,00 \\
600,00 \\
- \\
300,00 \\
170,00 \\
300,00\end{array}$ & $\begin{array}{c}- \\
- \\
600,00 \\
1900,00 \\
600,00 \\
- \\
300,00 \\
170,00 \\
300,00\end{array}$ & $\begin{array}{c}- \\
- \\
600,00 \\
1900,00 \\
600,00 \\
- \\
300,00 \\
170,00 \\
300,00\end{array}$ & $\begin{array}{c}150,00 \\
\overline{-} \\
150,00 \\
3000,00 \\
- \\
134,00 \\
500,00 \\
- \\
-\end{array}$ & $\begin{array}{r}75,00 \\
170,00 \\
295,00 \\
200,00 \\
600,00 \\
67,00 \\
310,00 \\
- \\
-\end{array}$ \\
\hline \multicolumn{7}{|l|}{ Micro-éléments } \\
\hline $\begin{array}{l}\mathrm{H}_{3} \mathrm{BO}_{3} \\
\mathrm{KI} \\
\mathrm{ZnSO}_{4}, 7 \mathrm{H}_{2} \mathrm{O} \\
\mathrm{MnSO}_{4}, \mathrm{H}_{2} \mathrm{O} \\
\mathrm{CuSO}_{4}, 5 \mathrm{H}_{2} \mathrm{O} \\
\mathrm{CoCL}_{2}, 6 \mathrm{H}_{2} \mathrm{O}\end{array}$ & $\begin{array}{c}3,00 \\
0,75 \\
2,00 \\
10,00 \\
0,025 \\
0,025\end{array}$ & $\begin{array}{c}3,00 \\
0,75 \\
2,00 \\
10,00 \\
0,025 \\
0,025\end{array}$ & $\begin{array}{c}3,00 \\
0,75 \\
2,00 \\
10,00 \\
0,025 \\
0,025\end{array}$ & $\begin{array}{c}3,00 \\
0,75 \\
2,00 \\
10,00 \\
0,025 \\
0,025\end{array}$ & $\begin{array}{c}3,00 \\
0,75 \\
2,00 \\
10,00 \\
0,025 \\
0,025\end{array}$ & $\begin{array}{c}3,00 \\
0,75 \\
2,00 \\
10,00 \\
0,025 \\
0,025\end{array}$ \\
\hline \multicolumn{7}{|l|}{ Vitamines } \\
\hline $\begin{array}{l}\text { Nicotinamide } \\
\text { Pyridoxine } \mathrm{HCl} \\
\text { Thiamine } \mathrm{HCl} \\
\text { D-Ca pantothénate } \\
\text { Acide folique } \\
\text { Acide p-amino benzoïque } \\
\text { Biotine } \\
\text { Chlorhydrate de choline } \\
\text { Riboflavine } \\
\text { Acide ascorbique } \\
\text { Vitamine } \mathrm{A} \\
\text { Vitamine } \mathrm{D}_{3} \\
\text { Vitamine } \mathrm{B}_{12} \\
\text { Acide nicotinique }\end{array}$ & $\begin{array}{l}1,00 \\
1,00 \\
10,00 \\
0,5 \\
0,2 \\
0,01 \\
0,005 \\
0,5 \\
0,1 \\
1,0 \\
0,005 \\
0,005 \\
0,01 \\
-\end{array}$ & $\begin{array}{l}1,00 \\
1,00 \\
10,00 \\
0,5 \\
0,2 \\
0,01 \\
0,005 \\
0,5 \\
0,1 \\
1,0 \\
0,005 \\
0,005 \\
0,01 \\
-\end{array}$ & $\begin{array}{l}1,00 \\
1,00 \\
1,00 \\
1,00 \\
0,4 \\
0,02 \\
0,01 \\
1,00 \\
0,20 \\
2,00 \\
0,01 \\
0,01 \\
0,02 \\
-\end{array}$ & $\begin{array}{l}1,00 \\
1,00 \\
10,00 \\
0,5 \\
0,2 \\
0,01 \\
0,005 \\
0,50 \\
0,10 \\
1,00 \\
0,005 \\
0,005 \\
0,01 \\
-\end{array}$ & $\begin{array}{l}\overline{1}, 00 \\
10,00 \\
= \\
= \\
\overline{-} \\
\overline{-} \\
\overline{-} \\
\overline{-} \\
\overline{1}, 00\end{array}$ & $\begin{array}{l}\overline{1} \\
10,00 \\
- \\
- \\
= \\
= \\
- \\
= \\
- \\
\overline{1} \\
1,00\end{array}$ \\
\hline \multicolumn{7}{|l|}{ Poly ols } \\
\hline $\begin{array}{l}\text { Inositol } \\
\text { Sorbitol } \\
\text { Mannitol }\end{array}$ & $\begin{array}{l}100,00 \\
125,00 \\
125,00\end{array}$ & $\begin{array}{l}100,00 \\
125,00 \\
125,00\end{array}$ & $\begin{array}{l}100,00 \\
250,00 \\
250,00\end{array}$ & $\begin{array}{l}100,00 \\
125,00 \\
125,00\end{array}$ & $\begin{array}{c}100,00 \\
- \\
-\end{array}$ & $\begin{array}{c}100,00 \\
- \\
-\end{array}$ \\
\hline $\begin{array}{l}\text { Oses } \\
\text { Glucose } \\
\text { Saccharose } \\
\text { Fructose } \\
\text { Ribose } \\
\text { Xylose } \\
\text { Mannose } \\
\text { Rhannose } \\
\text { Cellobiose }\end{array}$ & $\begin{array}{r}68400,00 \\
125,00 \\
125,00 \\
125,00 \\
125,00 \\
125,00 \\
125,00 \\
125,00\end{array}$ & $\begin{array}{r}10000,00 \\
20000,00 \\
125,00 \\
125,00 \\
125,00 \\
125,00 \\
125,00 \\
125,00\end{array}$ & $\begin{array}{r}68400,00 \\
250,00 \\
250,00 \\
250,00 \\
250,00 \\
250,00 \\
250,00 \\
250,00\end{array}$ & $\begin{array}{r}110400,00 \\
125,00 \\
125,00 \\
125,00 \\
125,00 \\
125,00 \\
125,00 \\
125,00\end{array}$ & $\begin{array}{c}20000,00 \\
- \\
- \\
- \\
- \\
-\end{array}$ & $\begin{array}{c}5000,00 \\
25000,00 \\
- \\
- \\
250,00 \\
- \\
- \\
-\end{array}$ \\
\hline \multicolumn{7}{|l|}{ Acides organiques } \\
\hline $\begin{array}{l}\text { Pyruvate de sodium } \\
\text { Acide citrique } \\
\text { Acide malique } \\
\text { Acide fumarique }\end{array}$ & $\begin{array}{r}5,00 \\
10,00 \\
10,00 \\
10,00\end{array}$ & $\begin{array}{r}5,00 \\
10,00 \\
10,00 \\
10,00\end{array}$ & $\begin{array}{l}20,00 \\
40,00 \\
40,00 \\
40,00\end{array}$ & $\begin{array}{r}5,00 \\
10,00 \\
10,00 \\
10,00\end{array}$ & $\begin{array}{l}- \\
- \\
-\end{array}$ & $\begin{array}{r}5,00 \\
10,00 \\
10,00 \\
10,00\end{array}$ \\
\hline $\begin{array}{l}\text { Sequestrène } 330 \mathrm{Fe} \\
\text { Fer-EDTA, } 10^{-2} \mathrm{M} \\
\mathrm{N}-\mathrm{Z} \text { amine } \\
\text { Lait de coco }\end{array}$ & $\begin{array}{r}28,00 \\
125,00 \\
10 \mathrm{ml}\end{array}$ & $\begin{array}{c}10 \mathrm{ml} \\
125,00 \\
-\end{array}$ & $\begin{array}{r}28,00 \\
\overline{250,00} \\
20 \mathrm{ml}\end{array}$ & $\begin{array}{l}- \\
10 \mathrm{ml} \\
125,00 \\
-\end{array}$ & $\begin{array}{l}28,00 \\
- \\
-\end{array}$ & $\begin{array}{l}28,00 \\
\overline{500,00} \\
-\end{array}$ \\
\hline \multicolumn{7}{|l|}{ Régulateurs de croissance } \\
\hline $\begin{array}{l}2,4 \mathrm{D} \\
\text { Zéatine } \\
\text { Zéatine riboside } \\
\text { A.N.A. }\end{array}$ & $\begin{array}{c}0,2 \\
0,5 \\
-1,0 \\
5,7, \mathrm{NaOH}\end{array}$ & $\begin{array}{c}0,1 \\
0,2 \\
- \\
1,0\end{array}$ & $\begin{array}{c}0,2 \\
0,5 \\
- \\
1,0\end{array}$ & $\begin{array}{c}0,2 \\
0,5 \\
-\quad \\
1,0\end{array}$ & $\begin{array}{c}2,0 \\
- \\
-\end{array}$ & $\begin{array}{c}0,5 \\
\overline{0,1} \\
-\end{array}$ \\
\hline
\end{tabular}




\section{Conclusion}

Le milieu définitivement retenu est le milieu $K_{795}$ (tabl. 3b).

Le pH est de 5,7, ajusté par $\mathrm{NaOH}$, puis le milieu est stérilisé par filtration.

Appelé $K_{795}$, ce milieu est très proche de celui utilisé par KAO \& MICHAYLUK (1980) pour la culture de protoplastes de $M$. sativa. Il est modifié par sa concentration en glucose, $110,4 \mathrm{~g} / 1$ au lieu de $68,4 \mathrm{~g} / 1$ et l'absence de lait de coco.

A l'exception de 2 clônes mâles stériles la majorité des génotypes testés produisent au moins quelques divisions sur le milieu $K_{795}$.

\section{Conduite de la culture des protoplastes}

\section{Environnement physique et mode de mise en cul- ture}

Trois modes de mise en culture ont été testés : le film liquide simple, le film liquide sur milieu solide, les goutelettes (tabl. 4). Bien que la technique de film liquide sur milieu solide avec un papier filtre intermédiaire utilisée par DOS SANTOS et al. (1980) et ARCIONI et al. (1982) donne de bons résultats, la culture en film liquide simple, à une densité de 50000 protoplastes par $\mathrm{ml}$ a été préférée. Elle permet, en effet, un bon suivi visuel des cultures.

La suspension de protoplastes est répartie à raison de $3 \mathrm{ml}$ par boîte de $5 \mathrm{~cm}$ de diamètre. Les boîtes sont scellées au parafilm.

\section{Entretien de la culture}

Pour initier la culture 3 températures : $22^{\circ} \mathrm{C}, 25^{\circ} \mathrm{C}$ et $28{ }^{\circ} \mathrm{C}$ ont été testées. La température de $28^{\circ} \mathrm{C}$ a été retenue pour conduire à un meilleur taux de division.

Sous une lumière continue (1 500 lux) ou sous une photopériode de $16 \mathrm{~h}$ les divisions apparaissent dès le $3^{\mathrm{e}}$ jour mais leur rythme ralentit après 8 jours jusqu'à s'arrêter vers le $15^{\mathrm{e}}$ jour. Par contre, lorsque les cultures sont placées à l'obscurité totale les premières divisions n'apparaissent qu'à partir du $5^{\mathrm{e}}$ jour mais se poursuivent régulièrement à raison d'une division tous les 2 jours environ. L'obscurité totale est donc préférable pour les premières étapes de la culture.

KAO \& MiCHAYLUK (1980) ont montré qu'il était nécessaire d'apporter du milieu frais aux cultures tout en diminuant progressivement la pression osmotique. Cette opération est réalisée ici avec un mélange du milieu $\mathrm{K}_{795}$ et d'un milieu de culture cellulaire $\left(\mathrm{K}_{4}\right.$ : KAO \& MiCHAYLUK, 1975) différant de $K_{795}$ par la concentration de glucose $(10 \mathrm{~g} / \mathrm{l})$, de saccharose $(20 \mathrm{~g} / \mathrm{l})$, de $2,4 \mathrm{D}(0,1 \mathrm{mg} / \mathrm{l})$ et de zéatine $(0,2 \mathrm{mg} / \mathrm{l})$.

La date et la composition du milieu de la première dilution sont particulièrement importantes (tabl. 5). Les cultures sont entretenues par la suite par apport d'un $\mathrm{ml}$ de milieu frais tous les 7 jours selon la séquence : $\mathrm{K}_{795}, \mathrm{FM}$ ( 3 vol. $\mathrm{K}_{795} / 1$ vol. $\mathrm{K}_{4}$ ), FM, FM (1 vol. $\mathrm{K}_{795} / 1$ vol. $\mathrm{K}_{4}$ ), $\mathrm{FM}_{2}, \mathrm{FM}_{2}$. Dans le même temps, les cultures sont exposées graduellement à la lumière à partir du $10^{\mathrm{e}}$ jour jusqu'à ce que l'intensité atteigne 2000 lux.

Après 28 jours de culture on observe 2 types de

TABLEAU 4

Effets de la densité et du mode de mise en culture sur la division des protoplastes et l'évolution des cultures. Effects of density and culture method on protoplast division and culture development.

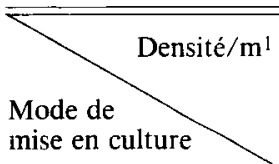

Film liquide simple certains reforment une pa- Quelques divisions initia- formation de cals et d'em- qui s'arrêtent très rapideroi. Aucune division. les puis arrêt des divisions. bryons (1). ment.

Apparition d'un dépôt brun entraînant la mort des cellules en quelques jours (2).

\begin{tabular}{|c|c|c|c|c|c|}
\hline \multirow{2}{*}{$\begin{array}{l}\text { Film } \\
\text { liquide } \\
\text { sur } \\
\text { milieu } \\
\text { solide }\end{array}$} & \multirow{2}{*}{$\begin{array}{c}\text { avec } \\
\text { papier } \\
\text { filtre } \\
\text { sans } \\
\text { papier } \\
\text { filtre }\end{array}$} & $\begin{array}{l}\text { Reconstitution des parois. } \\
\text { Très peu de divisions non } \\
\text { continues. }\end{array}$ & Comportement identique & $\begin{array}{l}\text { Comportement } \\
\text { semblable à (1) }\end{array}$ & $\begin{array}{l}\text { Comportement } \\
\text { semblable à (2) }\end{array}$ \\
\hline & & $\begin{array}{l}\text { Brunissement et mort des } \\
\text { protoplastes avant la } \\
\text { reconstitution des parois. }\end{array}$ & \multicolumn{3}{|c|}{ Comportement identique } \\
\hline \multicolumn{2}{|c|}{$\begin{array}{l}\text { Gouttelettes posées ou } \\
\text { en suspension. }\end{array}$} & $\begin{array}{l}\text { Un peu d'agglutination. } \\
\text { Quelques divisions mais } \\
\text { mort rapide des cellules } \\
\text { après } 8 \text { à } 15 \mathrm{j} \text { de culture. }\end{array}$ & $\begin{array}{l}\text { Beaucoup d'agglutination. } \\
\text { Nécrose des cellules. } \\
\text { Pas de divisions. }\end{array}$ & $\begin{array}{l}\text { Les protoplastes se rassem- } \\
\text { blent au centre et meurent } \\
\text { très rapidement. }\end{array}$ & Comportement identique \\
\hline
\end{tabular}


TABLEAU 5

Evolution des cultures de protoplastes de feuilles de luzerne selon la date et la nature de la première dilution.

Development of alfalfa mesophyll protoplast cultures according to the date and nature of the first dilution.

\begin{tabular}{|c|c|c|c|}
\hline $\begin{array}{l}\text { Nature dù } \\
\text { milieu apportê } \\
\text { lors de la } 1^{\text {te }} \text { dilution }\end{array}$ & $\mathrm{t}<5$ jours & 6 jours $<\mathrm{t}<8$ jours & $1<8$ jours \\
\hline $\mathrm{K}_{795}$ & $\begin{array}{l}\text { Bloquage des divisions puis mort } \\
\text { des cellules. }\end{array}$ & Poursuite des divisions. & Mort des protoplastes. \\
\hline $\mathrm{FM}$ & $\begin{array}{l}\text { Brunissement et mort des cellules } \\
\text { dans les } 48 \text { heures. }\end{array}$ & $\begin{array}{l}\text { Poursuite des divisions mais ralen- } \\
\text { tissement du rythme. Généralement } \\
\text { blocage à } 6-8 \text { cellules. }\end{array}$ & Mort des protoplastes. \\
\hline
\end{tabular}

structures : des cals et des embryons (fig. 1). Le contenu de chaque boîte est alors subdivisé pour permettre le bon développement des cultures.

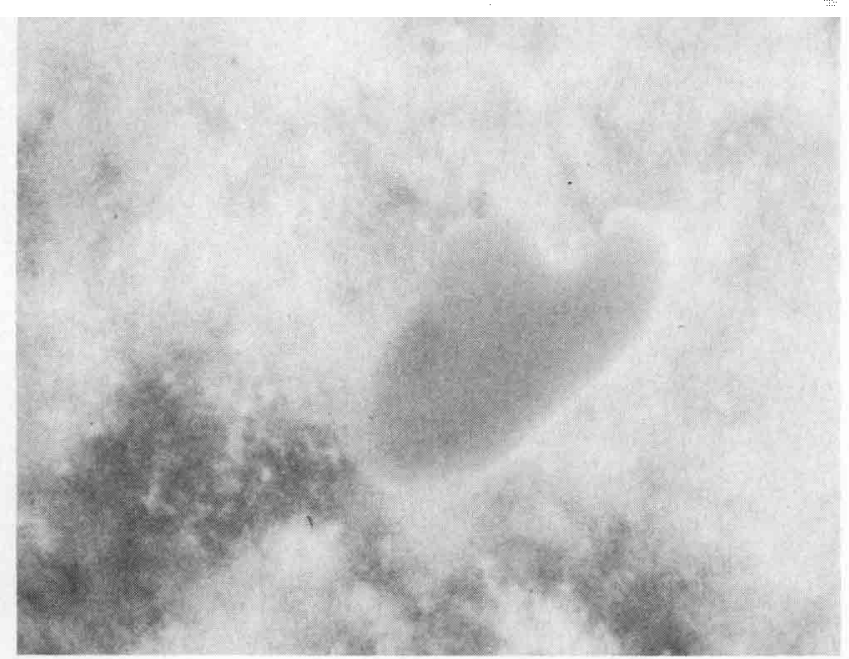

a)

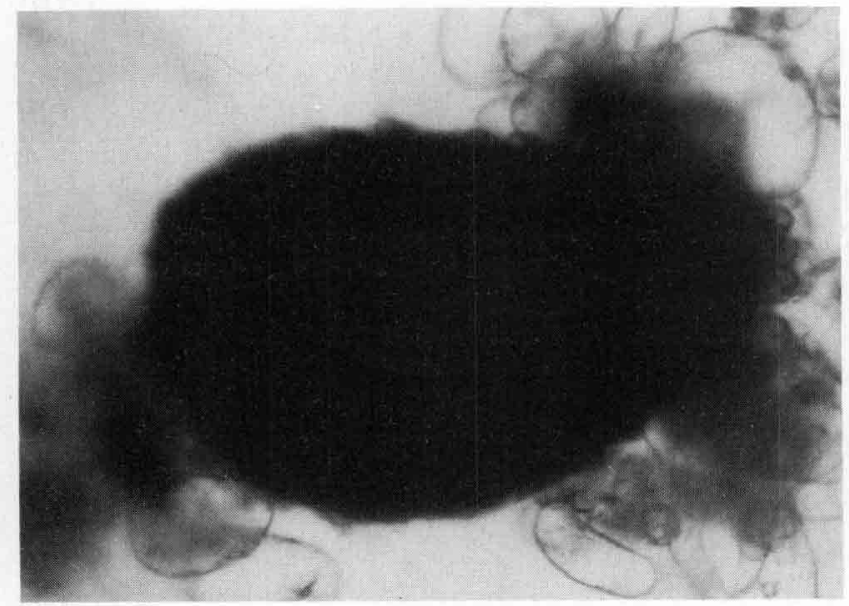

h)

Figure 1

Embryon (la) et cal (lb) obtenus par culture de protoplastes de mésophylle foliaire chez la luzerne.

Embryo (la) and callus (1b) obtained in protoplast culture derived from leaves of alfalfa.
A partir du $40^{\mathrm{e}}$ jour, un milieu de culture de cellules (milieu A), moins riche et sans régulateurs de croissance est ajouté (KAO \& MiCHAYLUK, 1980). Comme l'a signalé KAO (1980) l'addition à ce milieu de $10 \mathrm{~g} / \mathrm{l}$ d'amidon est très efficace pour tous les génotypes et favorise la croissance des embryons tout en évitant leur développement précoce en jeunes plantes.

Le milieu A enrichi d'amidon est donc ajouté à raison d'un ml tous les 7 jours jusqu'à ce que les embryons aient atteint la taille d'une graine mature et les cals 1 à $2 \mathrm{~mm}$ de diamètre. Le délai est au minimum d'un mois.

\section{Régénération des plantes}

\section{a) Culture des embryons}

Les embryons sont prélevés individuellement et placés dans des boîtes de Pétri sur un papier filtre stérile imbibé de milieu A sans amidon. Ils sont cultivés à $25^{\circ} \mathrm{C}$ sous 3000 lux. Dès que le système racinaire est suffisamment développé, les jeunes plantes sont repiquées dans un mélange $(1 / 1)$ de terreau et de vermiculite (fig. 2).

\section{b) Culture des cals}

Deux séquences de milieu solide induisant la régénération à partir de cals issus d'explants somatiques de $M$. sativa ont été essayées :

- séquence sur milieux de BlAydes (SAUNDERS \& BINGHAM, 1972),

- séquence sur les milieux d'UCHIMIYA \& MURASHIGE et de MuRASHIGE \& SKOOG. Les cals sont placés 28 jours sur le milieu UM d'UCHIMIYA \& MURASHIGE (1974) puis transférés sur le milieu $\mathrm{MSD}_{4}$ de MURASHIGE \& SKOOG (1962).

La séquence sur les milieux de BLAYDES est inefficace sur les cals issus de protoplastes. Par contre sur la séquence de milieux UM et $\mathrm{MSD}_{4}$ on obtient des bourgeons qui, transférés sur milieu de MURASHIGE \& SKOOG sans régulateurs de croissance forment des racines. Les plantes ainsi obtenues sont ensuite traitées de la même façon que celles provenant d'embryons.

\section{HYBRIDATION SOMATIQUE}

Deux méthodes ont été tentées : la fusion avec le polyéthylène glycol (P.E.G.) et la fusion avec les sels de calcium à $\mathrm{pH}$ élevé. 


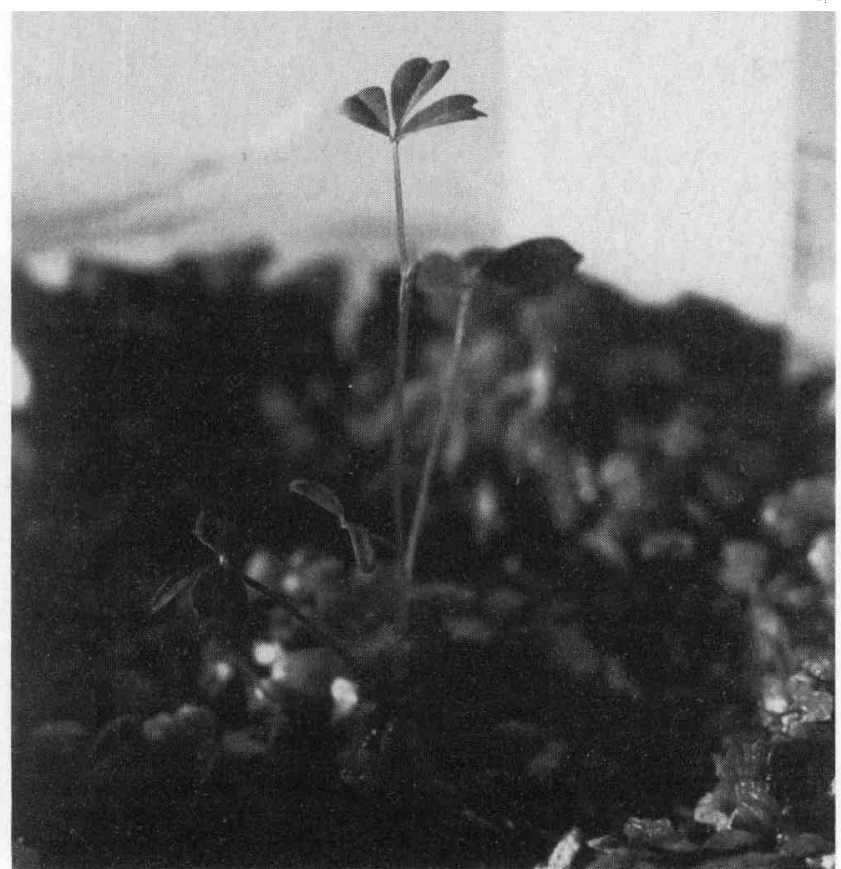

Figure 2

Jeune plante issue de culture de protoplaste après transplantation. Plantlet derived from protoplast culture after transplantation.

\section{A. Résultats de la fusion avec le P.E.G.}

La solution de fusion essayée sur des protoplastes de $M$. sativa et de $M$. falcata purs ou en mélange est composée de $\mathrm{CaCl}_{2} 2 \mathrm{H}_{2} \mathrm{O}: 0,01 \mathrm{M}, \mathrm{KH}_{2} \mathrm{PO}_{4}: 0,7 \mathrm{mM}$, de saccharose ou de glucose : $0,05 \mathrm{M}$ et de P.E.G. 1540 ou 6000 dans des concentrations variant de 20 à 50 p. 100 . Le temps d'incubation varie de 15 à $25 \mathrm{mn}$.

Les protoplastes supportent le contact avec la solution de P.E.G. mais la mortalité est souvent élevée (tabl. 6).

Le rinçage est effectué soit avec le milieu $\mathrm{K}_{795}$ soit avec une solution CPW $13 \mathrm{M} / \mathrm{Ca}$ comprenant les sels de FREARSON (FREARSON et al., 1973), 0,71 M de

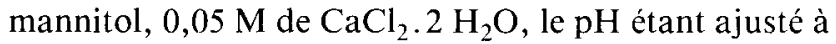
5,8 par $\mathrm{NaOH}$.

L'effet du mode de rinçage apparaît au bout de 8 jours. Les protoplastes rincés avec la solution saline $\mathrm{CPW} 13 \mathrm{M} / \mathrm{Ca}$ brunissent et meurent avant la première division, seuls les protoplastes rincés avec le milieu $\mathrm{K}_{795}$ se divisent.

Par ailleurs, avec le P.E.G. 1540 les protoplastes s'agglutinent mais ne fusionnent pas; avec le P.E.G. 6000 les protoplastes ne fusionnent que si la concentration en P.E.G. est supérieure à 20 p. 100. A partir de 30 p. 100 de P.E.G. 6000 la fusion se produit mais la mortalité est élevée (tabl. 6).

Le contrôle cytologique du taux de fusion après fixation (MAGNIEN, 1981) et coloration par la réaction de FEULGEN permet d'évaluer à $20 \mathrm{p} .100$ le total des auto et des allofusions avec 30 p. 100 de P.E.G. 6000 pendant 15 ou $20 \mathrm{mn}$. Cependant l'évolution des cultures s'arrête au stade 6 à 8 cellules et aucune plante n'a pu être obtenue à la suite de ce mode de traitement. Des tentatives de fusion en tube, technique permettant de mieux éliminer le P.E.G. que la technique en gouttelettes (KAO \& MiCHAYLUK, 1974) précédemment utilisée, ainsi que des tests sur la nature du sucre dans la solution de fusion n'ont pas permis d'améliorer ce résultat.

Par ailleurs, il est à noter que l'effet néfaste du P.E.G. se manifeste plus rapidement sur les cultures de $M$. sativa que sur les cultures de $M$. falcata.

TABLEAU 6

Etat des protoplastes $24 \mathrm{~h}$ après la fusion selon le temps d'incubation et la concentration en P.E.G. State of protoplasts $24 \mathrm{~h}$ after fusion according to incubation time and polyethylene glycol.

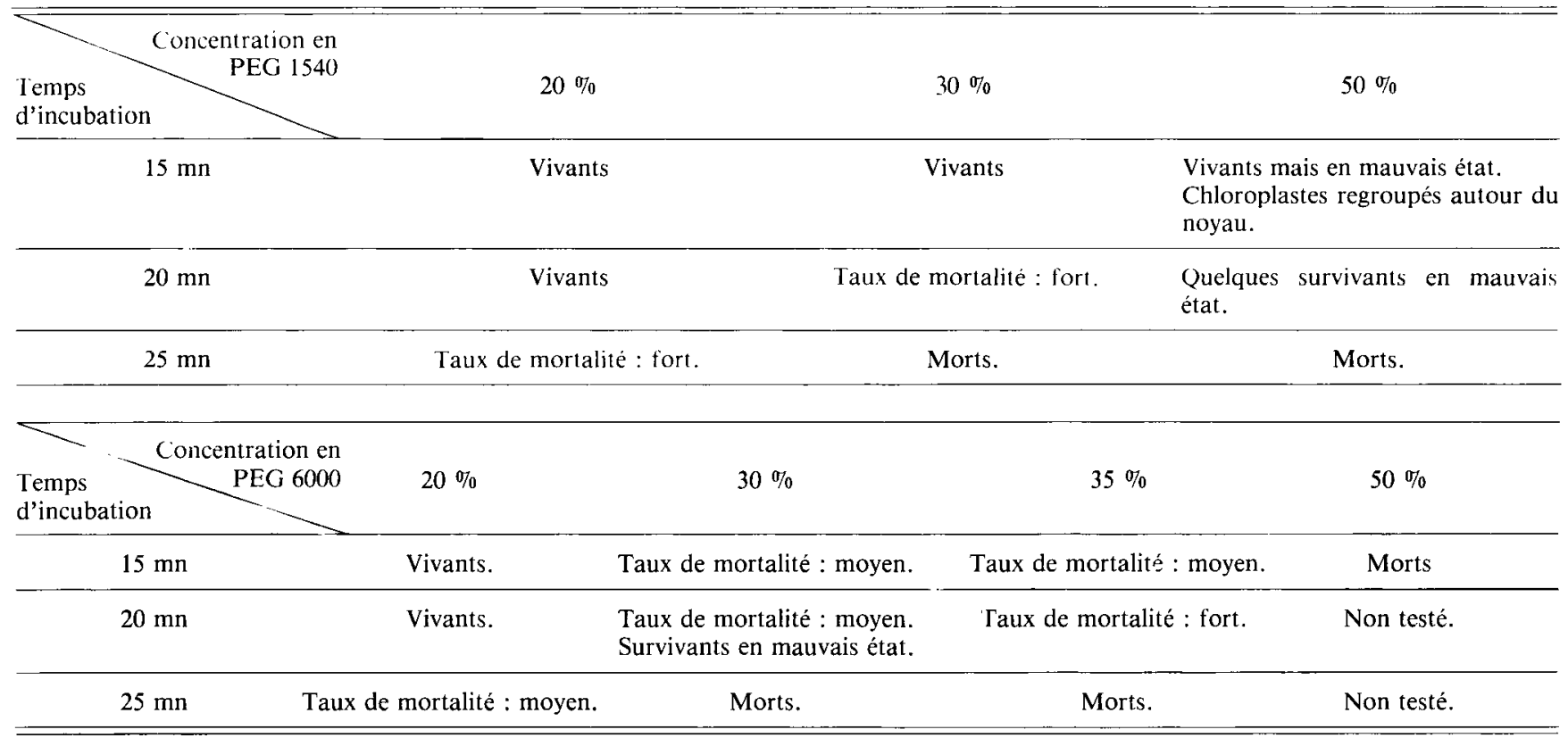




\section{B. Résultat de la fusion utilisant le chlorure de cal- cium à $\mathbf{p H}$ élevé}

La méthode utilisant les sels de calcium à $\mathrm{pH}$ élevé mise au point par Keller \& MELCHERS (1973) est rarement employée car elle conduit à des taux de fusion généralement faibles.

Chez Medicago la fusion au chlorure de calcium a été pratiquée en tubes. Les protoplastes sont concentrés dans le milieu $\mathrm{K}_{795}$ à 500000 protoplastes par ml puis répartis dans les tubes à raison de $1 \mathrm{ml}$ par tube et de $2 \mathrm{ml}$ de solution de fusion $\left(0,112 \mathrm{M}\right.$ de $\mathrm{CaCl}_{2}$. $2 \mathrm{H}_{2} \mathrm{O}, 0,5 \mathrm{M}$ de mannitol dissous dans du tampon glycine $0,05 \mathrm{M}$ à $\mathrm{pH}=10,4$; d'après KELLER \& MELCHERS, 1973). Les tubes sont placés à $32^{\circ} \mathrm{C}$ ou $37^{\circ} \mathrm{C}$ pendant 10 à $20 \mathrm{mn}$. Les préparations sont ensuite centrifugées à $60 \mathrm{~g}$ pendant $5 \mathrm{mn}$, le surnageant est ôté et les protoplastes sont rincés 2 fois avec le milieu $K_{795}$ ou la solution CPW $13 \mathrm{M} / \mathrm{Ca}$. Ils sont ensuite mis en culture dans le milieu $\mathrm{K}_{795}$. Pour les génotypes de $M$. sativa et $M$. falcata, ce traitement n'entraîne pas un taux de mortalité plus élevé que dans les cultures sans fusion. Par contre, le taux de fusion est assez faible, 5 à 10 p. 100 et aucune augmentation n'a pu être obtenue par la modification de divers facteurs (température, durée d'incubation, concentration en calcium de la solution de fusion). La solution initiale a donc été conservée et la durée d'incubation fixée à $15 \mathrm{mn}$ à $32{ }^{\circ} \mathrm{C}$. Les protoplastes ainsi obtenus sont en bon état et aptes à se diviser.

Le choix de la solution de rinçage est important car il permet de limiter l'agglutination des protoplastes après la fusion. Un premier rinçage avec la solution saline $\mathrm{CPW} 13 \mathrm{M} / \mathrm{Ca}$ et un deuxième avec le milieu de culture $\mathrm{K}_{795}$ constituent le traitement le plus approprié.

Une conséquence de ce mode de fusion est un retard à la première division : dans les cultures ayant subi le traitement de fusion au calcium, les divisions n'apparaissent qu'au $7^{\mathrm{e}}$ ou $8^{\mathrm{e}}$ jour, ce qui représente 2 à 3 jours de retard par rapport à une évolution normale de la culture.

Par contre et contrairement au traitement avec le P.E.G., il est possible d'obtenir des plantes entières à partir des populations de protoplastes ayant subi une opération de fusion au calcium à $\mathrm{pH}$ élevé, et conduites ensuite selon le mode de culture exposé précédemment. Il a été montré que certaines d'entre elles résultaient de la fusion entre les 2 génotypes parentaux (TÉOULÉ, 1983a, 1983b) (fig. 3).

\section{DISCUSSION}

Plusieurs points peuvent être dégagés. Ils concernent la diversification des génotypes susceptibles de régénérer des plantes après culture de protoplastes de $M$. sativa, l'obtention de régénérations à partir de protoplastes de $M$. falcata et la mise au point d'une méthode d'hybridation somatique entre 2 espèces du genre Medicago.

La méthode de culture de protoplastes sans opération de fusion présentée ici dérive assez directement de celle décrite par KAO \& MiCHAYLUK (1980). La différence essentielle porte sur le prétraitement des plantes : le passage en photopériode courte avant l'isolement

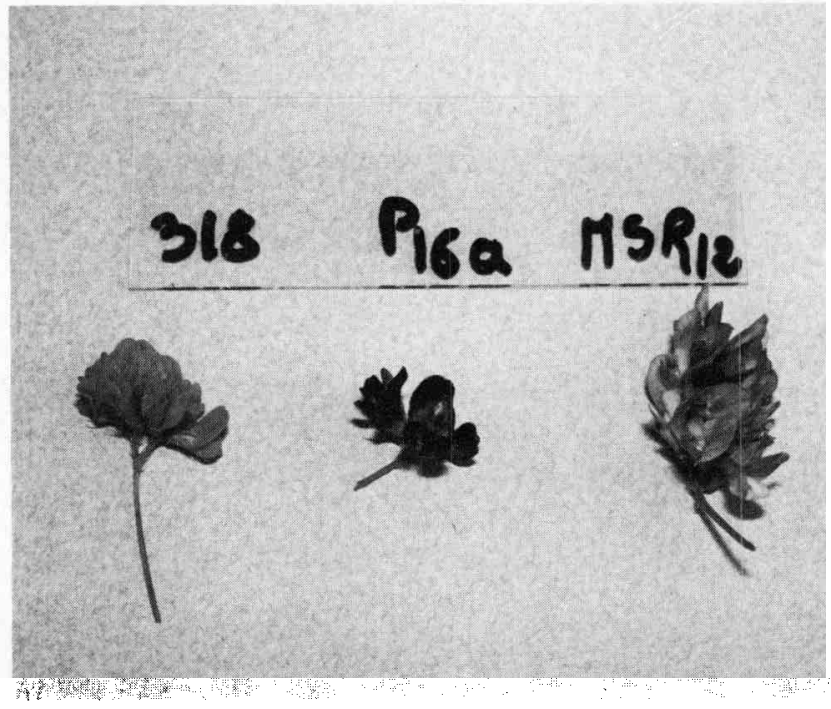

Figure 3

Inflorescence des 2 génotypes parentaux et d'un hybride somatique régénéré après l'opération de fusion au $\mathrm{CaCl}_{2}$.

$318 \quad$ :Génotype parental Medicago falcata.

MSR 12 : Génotype parental Mediago sativa.

P I6a : Hybride somatique issu de la fusion entre 318 et MSR 12. Inflorescences of the 2 parents and one somatic hybrid derived from fusion experiment with $\mathrm{CaCl}_{2}$.

318 : Medicago falcata parental genotype.

MSR 12: Medicago sativa parental genotype.

$P 16 a$ : Somatic hybrid between 318 et MSR 12

des protoplastes est très bénéfique, même sur des plantes adultes dans la mesure où l'on prélève les jeunes feuilles. Elle présente l'avantage d'être adaptée à diverses origines génétiques de $M$. sativa puisque des plantes ont pu être obtenues à partir de génotypes des cultivars Europe et Verneuil et de la population chinoise.

Ces résultats qui s'ajoutent à ceux précédemment décrits dans la littérature (KAO \& MICHAYLUK, 1980 ; JOHNSON et al., 1981; DOS SANTOS et al., 1980; ARCIONI et al., 1982 ; ATANOSSOV \& BROWN, 1983), montrent que $M$. sativa est certainement parmi les Légumineuses l'espèce chez laquelle la culture de protoplastes est actuellement la mieux maîtrisée. En effet, compte tenu de la forte variabilité génétique intraspécifique et même intra-cultivar, il est évident que l'ensemble des régénérations décrites porte sur des génotypes très divers. Cet aspect est d'ores et déjà essentiel pour un objectif d'application en sélection.

Cependant, d'importantes différences de réponses en culture subsistent : certains clônes mâles stériles cytoplasmiques ont produit des protoplastes qui ne se sont pas divisés, d'autres clônes ou populations ont produit des cals non morphogènes. Les travaux de KAO \& MICHAYLUK (1980) aboutissent à la même conclusion : au sein d'un même cultivar et entre 8 plantes l'efficacité d'étalement varie de 0 à 70 p. 100 et la formation d'embryons de 0 à plus de 50 p. 100 . Les différences individuelles dans une même population sont d'amplitude variable. Ainsi elles sont presque nulles au sein de la population chinoise qui donne toujours de bosn résultats, mais très marquées dans les populations Provence et Flamande où, selon les individus, le taux de division des protoplastes varie de 0 à $40 \mathrm{p} .100$. Toutefois, aucune raison ne permet de penser que la 
base génétique des 2 dernières populations soit plus large que celle de la population chinoise.

Dans l'état actuel des objectifs d'utilisation en sélection, la spécificité génétique n'est pas un facteur limitant puisqu'il a été montré que des origines très différentes étaients susceptibles de conduire à des régénérations. Si toutefois l'utilisation de génotypes particuliers et pour lesquels la technique serait inadaptée s'avérait indispensable, il serait nécessaire de procéder à des ajustements plus spécifiques.

Par ailleurs, des régénérations ont aussi été obtenues avec la même méthode à partir de culture de protoplastes de Medicago falcata. Ce résultat, qui n'avait pas encore été établi est, lui aussi, important pour l'introduction des cultures de protoplastes dans les schémas de sélection.

Cependant la seule régénération de plantes après culture de protoplastes ne constitue pas en soi une étape suffisante pour une application pratique. Il est en effet nécessaire de maîtriser également la technique de fusion. C'est pourquoi le résultat le plus important de l'expérimentation est certainement l'obtention de plantes viables après l'opération de fusion somatique par le chlorure de calcium. Une quarantaine de plantes ont été obtenues après la confrontation des protoplastes d'un clône mâle stérile cytoplasmique de $M$. sativa et d'un clône de $M$. falcata. Pour certaines d'entre elles la preuve d'une hybridation totale, au moins au niveau nucléaire a été apportée. D’autres plantes résultent de fusions partielles. Une plante issue d'autofusion de M. falcata a aussi été régénérée (TÉOULÉ, 1983a, $1983 b$ ). L'ensemble des plantes fait actuellement l'objet d'analyses génétiques.

\section{CONCLUSION}

D'après les présents résultats, ceux de KAO \& MICHAYLUK (1980), DOS SANTOS et al. (1980), JOHNSON et al. (1981), LU et al. (1982), ARCIONI et al. (1982), 4 espèces du genre Medicago: $M$. sativa, $M$. falcata, $M$. coerulea et $M$. glutinosa peuvent être utilisées en culture de protoplastes et régénérer des plantes. De plus, chez Medicago sativa, les origines génétiques peuvent être diversifiées.

Par ailleurs, la mise au point d'une technique de fusion de protoplastes ouvre la possibilité d'obtenir des hybrides somatiques interspécifiques.

Pour la sélection de la luzerne, qui s'est effectuée jusqu'à maintenant essentiellement par la voie intraspécifique, l'hybridation somatique constitue une possibilité nouvelle et intéressante au plan agronomique. Le genre Medicago comprend en effet de très nombreuses espèces de caractéristiques agronomiques et physiologiques très variées. L'objectif est donc d'étendre les expérimentations d'hybridation somatique à d'autres espèces et en particulier à des formes diploïdes spontanées pour restituer l'état tétraploïde dans les produits de fusion.

Reçu le 4 août 1986 Accepté le 14 mai 1987.

\section{REMERCIEMENTS}

Les auteurs remercient le Ministère de l'Agriculture, l'A.C.V.F. et l'A.D.A.R. pour le soutien de cette recherche.

\section{RÉFÉRENCES BIBLIOGRAPHIQUES}

Ahuja P. S., Hadiuzzaman S., Davey M. R., Cocking E. C., 1983. Prolific plant regeneration from protoplast-derived tissues of Lotus corniculatus L. (Birdsfoot Trefoil). Plant Cell Reports, 2, 101-104.

Arcioni S., Mariotti D., 1983. Tissue culture and plant regeneration in Onobrychis viciaefolia Scop. Z. Pflanzenzüchtg., 90, 3, 192-197.

Arcioni S., Davey M. R., Dos Santos A. V. P., Cocking E. C., 1982. Somatic embryogenesis in tissues from mesophyll and cell suspension protoplasts of Medicago coerulea and Medicago glutinosa. Z. Pflanzenphysiol., 106, 105-110.

Atanassov A. I., Brown D. C. W., 1983. Plant regeneration from suspension culture and mesophyll protoplasts of alfalfa. In I. Potrykus et al. Protoplasts 83, Poster proceedings, 6th International Protoplast Symposium, Bâle, 12-16 août 1983, Birkhäuser Verlag.

Beach K. H., Smith R. R., 1979. Plant regeneration from callus of red and crimson clover. Plant Science Letters, 16, 231-237.

Bingham E. T., Hursley L. V., Kaatz D. M., Saunders J. W., 1975. Breeding alfalfa which regenerates from callus tissue in culture. Crop Sci., 15, 719-720.

Brown D. C. W., Atanassov A., 1985. Role of genetic background in somatic embryogenesis in Medicago. Plant Cell Tissue and Organ culture, 4, 2, 111.

Frearson E. M., Power J. B., Cocking E. C., 1973. The isolation, culture and regeneration of Petunia leaf protoplasts. Dev. Biol., 33, 130-137.

Galzy R., Hamoui M., 1980. Induction de l'organogenèse sur des cals de Vicia faba minor provenant d'apex. Can. J. Bot., 59, 203206 .

Gamborg O. L., Miller R. A., Ojima K., 1968. Nutrient requirements of suspension cultures of soybean root cells. Exp. Cell. Res., 50, $151-158$.
Gresshoff P. M., 1980. In vitro culture of white clover : callus, suspension, protoplast culture and plant regeneration. Bot. Gaz., 141 (2), 157-164

Grosser J. W., Collins G. B., 1984. Isolation and culture of Trifolium rubens protoplasts with whole plant regeneration. Plant Science Letters, 37, 165-170.

Hartman C. L., Mc Coy T. J., Knous T. R., 1984. Selection of alfalfa (Medicago sativa) cell lines and regeneration of plants resistant to the toxin(s) produced by Fusarium oxysporum f. sp. medicaginis. Plant Science Letters, 34, 183-194.

Jacobsen H. J., Kisely W., 1984. Induction of somatic embryos in pea, Pisum sativum L. Plant Cell, Tissue and Organ Culture, 3 (4), 319-324.

Johnson L. B., Stuteville D. L., Higgins R. K., Skinner D. Z., 1981. Regeneration of alfalfa plants from protoplast selected Regen. S clones. Plant Science Letters, 20, 297-304.

Kameya T., Widholm J., 1981. Plant regeneration from hypocotyl sections of Glycine species. Plant Science Letters, 21, 289-294.

Kao K. N., 1977. Chromosomal behaviour in somatic hybrids of soybean Nicotiana glauca. Molec. gen. Genet., 150, 225-230.

Kao K. N., Michayluk M. R., 1974. A method for high frequency intergeneric fusion of plant protoplasts. Planta, 115, 355-367.

Kao K. N., Michayluk M. R., 1975. Nutritional requirements for growth of Vicia hajastana cells and protoplasts at a very low population density in liquid media. Planta, 126, 105-110.

Kao K. N., Michayluk M. R., 1980. Plant regeneration from mesophyll protoplasts of alfalfa. Z. Pflanzenphysiol., 96, 135-141.

Kao K. N., Michayluk M. R., 1981. Embryoid formation in alfalfa cell suspension cultures from different plants. In vitro, 17 (7), 645648 . 
Keller W. A., Melchers G., 1973. Effect of high pH and calcium on tobacco leaf protoplast fusion. Z. Naturforsch., 28c, 737-741.

Lu D. Y., Davey M. R., Pental D., Cocking E. C., 1982. Somatic embryogenesis from protoplasts of seedling cotyledons and roots of Medicago sativa. In : A. Fujiwara : Proceedings of the 5th International Congress of Plant Tissue and Cell Culture. Tokyo, juillet 1982.

Lu D. Y., Davey M. R., Cocking E. C., 1982. Somatic embryogenesis from mesophyll protoplasts of Trigonella corniculata (Leguminosae). Plant Cell Reports, 1, 278-280.

Lupotto E., 1983. Propagation of an embryogenic culture of Medicago sativa L. Z. Pflanzenphysiol., 111, 95-104.

Magnien E., 1981. Sensibilité des protoplastes de Nicotiana sp. aux rayonnements ionisants. Thèse de Doc. Ing., Univ. Paris-Sud, 190 p., 2 pl.

Malmberg R. L., 1979. Regeneration of whole plants from callus culture of diverse genetic lines of Pisum sativum L. Planta, 146, 243244.

Mariotti O., Pezzotti M., Falistocco E., Arcioni S., 1984. Plant regeneration from leaf-derived callus of Lotus corniculatus L. cv. Franco. Genet. Agr., 38, 219-232.

Mariotti D., Arcioni S., Pezzotti M., 1984. Regeneration of Medicago arborea $\mathrm{L}$. plants from tissue and protoplast cultures of different organ origin. Plant Science Letters, 37, 149-156.

MacCoy T. J., Bingham E. T., 1977. Regeneration of diploid alfalfa plants from cells grown in suspension culture. Plant Science Letters, $10,59-66$.

Meijer E. G. M., 1982. High frequency plant regeneration from hypocotyl and leaf-derived tissue cultures of the tropical pasture legume Stylosanthes humilis. Physiol. Plant., 56, 381-385.

Mitten D. H., Sato S. J., Skokut T. A., 1984. In vitro regenerative potential of alfalfa germplasm sources. Crop Sci., 24, 943-945.

Mokhtarzadeh A., Constantin M. J., 1978. Plant regeneration from hypocotyl and anther-derived callus of Berseem clover. Crop Sci., 18, 567-572.

Murashige T., Skoog F., 1962. A revised medium for rapid growth and bioassay with tobacco tissue culture. Physiol. Plant., 15, 473-497.

Oswald T. H., Smith A. E., Phillips P. V., 1977. Callus and plantlet regeneration from cell cultures of ladino clover and soybean. Physiol. Plant., 39, 129-133.

Pelletier G., Pelletier A., 1971. Culture in vitro de tissus de trèfle blanc (Trifolium repens); variabilité des plantes régénérées. $A n n$. Amélior. Plantes, 21 (2), 221-233.
Pezzotti M., Arcioni S., Mariotti D., 1984. Plant regeneration from mesophyll, root and cell suspension protoplasts of Medicago sativa cv. Adriana Genet. Agr., 38, 195-208.

Phillips G. C., Collins G. B., 1979. In vitro tissue culture of selected legumes and plant regeneration from callus cultures of red clover. Crop Sci., 19, 59-64.

Reisch B., Bingham E. T., 1980. The genetic control of bud formation from callus cultures of diploid alfalfa. Plant Science Letters, 20, 71-77.

Dos Santos A. V. P., Outka D. E., Cocking E. C., Davey M. R., 1980. Organogenesis and somatic embryogenesis in tissues derived from leaf protoplasts and leaf explants of Medicago sativa. Z. Pflanzenphysiol., 99, 261-270.

Saunders J. W., Bingham E. T., 1972. Production of alfalfa plants from callus tissue. Crop Sci., 12, 804-808.

Saunders J. W., Bingham E. T., 1975. Growth regulator effects on but initiation in callus cultures of Medicago salla. Am. J. Bot., 62 , 850-855.

Stuart D. A., Strickland S. G., 1984. Somatic embryogenesis from cell cultures of Medicago sativa L. I. The role of amino acid conditions to the regeneration medium. II. The interaction of amino acids with ammonium. Plant. Sci. Lett., 34, 165-174, 175-181.

Téoulé E., 1983a. Hybridation somatique dans le genre Medicago. Mise au point de la technique. Caractéristiques des premières plantes régénérées. Thèse Docteur-Ingénieur, Université de Paris-Sud, Orsay, $119 \mathrm{p}$.

Téoulé E., 1983b. Hybridation somatique entre Medicago sativa $\mathrm{L}$. et Medicago falcata. C. R. Acad. Sci. Paris, Ser. III, 297, 13-16.

Uchimiya H., Murashige T., 1974. Evaluation of parameters in the isolation of viable protoplasts from cultured tobacco cells. Plant Physiol., 54, 936-944.

Walker K. A., Sato S. J., 1981. Morphogenesis in callus tissue of Medicago sativa: the role of ammonium ion in somatic embryogenesis. Plant Cell Tissue Organ Culture, 1, 109-121.

Walker K. A., Yu P. C., Sato S. J., Jaworski E. G., 1978. The hormonal control of organ formation in callus of Medicago sativa $\mathrm{L}$. cultured in vitro. Amer J. Bot., 65, 654-659.

Walker K. A., Wendeln M. L., Jaworski E. G., 1979. Organogenesis in callus tissue of Medicago sativa. The temporal separation of induction processes from differentiation processes. Plant Science Letters, 16, 23-30.

Xu Z. H., Davey M. R., Cocking E. C., 1981. Isolation and sustained division of Phaseolus aureus (mung bean) root protoplasts. Z. Pflanzenphysiol., 104, 289-298. 